\title{
Long-term management of children with neuromuscular disorders
}

\author{
Eugen-Matthias Strehle*
}

\begin{abstract}
Objective: Duchenne muscular dystrophy is the commonest genetic myopathy but there exist a large number of inherited neuromuscular diseases which individually are very rare and where clinical information is not widely available. This review is based on the author's experience in a pediatric muscle clinic and provides practical guidance and treatment plans for frequently encountered problems.

Sources: A MEDLINE search was conducted to retrieve recent articles relevant to the management of children with inherited myopathies and neuropathies. A patient cohort $(n=200)$ was evaluated using descriptive statistics.

Summary of the findings: Duchenne muscular dystrophy accounted for almost half of the diagnoses, followed by spinal muscular atrophy (12\%), Becker muscular dystrophy and myotonic dystrophy ( $7 \%$ each). Sixteen patients ( $9 \%$ ) had an unknown myopathy.

Conclusions: As with other chronic illnesses, these patients should be regularly reviewed by health professionals from an early age to increase life expectancy and improve quality of life. It is useful for physicians to take a structured approach when looking after children with neuromuscular disorders and to monitor all affected organ systems.
\end{abstract}

J Pediatr (Rio J). 2009;85(5):379-384: Neuromuscular disorders, myopathy, neuropathy, children, management, follow-up.

\section{Introduction}

Inherited neuromuscular disorders (NMDs) affect approximately one in 3,500 children worldwide, and Xlinked Duchenne muscular dystrophy (DMD) has the highest incidence among them. Many conditions present with muscle weakness and wasting and can be diagnosed by genetic mutation analysis alone, but muscle, skin or nerve biopsy still remain important diagnostic tools. Although various strategies for genetic therapies of these diseases are being explored, the cornerstones of current treatment are symptomatic and supportive healthcare. ${ }^{1,2}$ Comprehensive reviews on specific NMDs have been published but it can be a challenge for the novice or the busy clinician to keep up to date with the latest literature when looking after children suffering from a wide range of rare disorders. ${ }^{3-5}$ However, when monitoring these chronically ill patients over a prolonged period, certain recurring themes can be observed that are pertinent to most NMDs. These themes can be ascribed to the specific muscle or nerve pathology and its effect on other systems of the body. Here, the author describes his experience of following up 200 children presenting to a pediatric muscle clinic during a 3-year period.

* MD. MSc. MPhil. Consultant Pediatrician, Honorary Consultant in Neuromuscular Genetics, Department of Pediatrics, North Tyneside General Hospital, Rake Lane, North Shields, United Kingdom.

No conflicts of interest declared concerning the publication of this article.

Suggested citation: Strehle EM. Long-term management of children with neuromuscular disorders. J Pediatr (Rio J). 2009;85(5):379-384.

Manuscript submitted Mar 30 2009, accepted for publication May 52009.

doi:10.2223/JPED.1929 


\section{Clinics}

The young patients were reviewed on average twice a year by a multidisciplinary team consisting of three to five doctors (at least one of them senior), one to three specialist physiotherapists, two pediatric nurses, one genetic counselor and one social care advisor. A psychologist would have been desirable but was not routinely available. To reduce travelling for the families, one of the appointments was scheduled at the regional genetics center and the other at a district general hospital close to their homes. This meant that the pediatric muscle team held regular outreach clinics covering on average 100 miles in a day. The age of the predominantly male patients ranged from 1.9 to 19.8 years with a mean age of 11.5 years (Figure 1 ). The children comprised $44 \%$ of all young patients reviewed during that period, and only a small proportion was seen by the author twice. Almost half of the patients (45\%) had DMD, followed by spinal muscular atrophy (SMA), Becker muscular dystrophy (BMD) and congenital myotonic dystrophy (MD). A relatively large proportion of children ( $9 \%$ ) had an unknown myopathy where a specific diagnosis had not been reached despite extensive investigations. In some cases, a diagnosis was made after several years in the light of new research findings. Hospital database entries were incomplete for 30 patients (15\%). The remaining 170 patients presented with 18 different diagnoses (Table 1).

\section{Systems}

\section{Muscular}

At each 1-hour assessment a detailed medical history with emphasis on mobility covering the preceding months was obtained, and any concerns raised by the parent/caregiver or patient were addressed. Muscle strength was measured using the Medical Research Council grading: 1 = flicker or trace of contraction, 2 = active movement with gravity

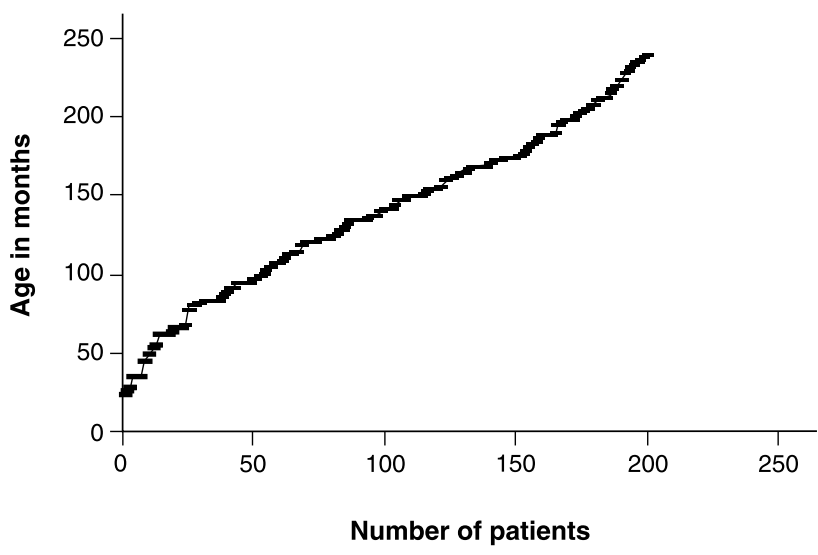

Figure 1 - Age distribution of 200 children with neuromuscular conditions

Table 1 - Spectrum of neuromuscular diseases encountered in a pediatric muscle clinic $(n=170)$

\begin{tabular}{|c|c|}
\hline Disease & n (\%) \\
\hline Duchenne muscular dystrophy & $77(45)$ \\
\hline Spinal muscular atrophy & $21(12)$ \\
\hline Unknown myopathy & $16(9)$ \\
\hline Becker muscular dystrophy & $12(7)$ \\
\hline Myotonic dystrophy & $11(7)$ \\
\hline Merosin-negative congenital muscular dystrophy & $5(3)$ \\
\hline Bethlem myopathy & $4(2)$ \\
\hline Central core disease & $4(2)$ \\
\hline Charcot-Marie-Tooth disease & $4(2)$ \\
\hline Nemaline myopathy & $3(2)$ \\
\hline Ullrich congenital muscular dystrophy & $3(2)$ \\
\hline Facioscapulohumeral muscular dystrophy & $2(1)$ \\
\hline Fukuyama congenital muscular dystrophy & $2(1)$ \\
\hline Walker-Warburg syndrome & $2(1)$ \\
\hline Autosomal recessive limb girdle muscular dystrophy & $1(1)$ \\
\hline Myotubular myopathy & $1(1)$ \\
\hline Rigid spine muscular dystrophy & $1(1)$ \\
\hline X-linked myopathy with excessive autophagy & $1(1)$ \\
\hline
\end{tabular}


eliminated, $3=$ active movement against gravity, $4=$ active movement against gravity and resistance, $5=$ normal power. As a minimum timed tests for rising from the floor, running $10 \mathrm{~m}$ and climbing four stairs up and down were performed on all ambulant children. Boys with DMD also underwent a North Star Ambulatory Assessment which measures levels of activity and gives a maximum score of $34 .{ }^{6}$ Non-ambulant children were assessed using the Egen Classification Scale Version 2.7 Most children received regular physiotherapy, and their parents were reminded of the importance of daily home stretching exercises to prevent contractures. Physical activity that was highly competitive or carried an increased risk of injury was not recommended. If ankle dorsiflexion was not possible beyond the neutral position, night splints were prescribed for ambulant children and day splints for those in wheelchairs. Manual and electric wheelchairs were regularly maintained to ensure a comfortable sitting position. Some young people with DMD benefitted from a standing frame, swivel walker or knee-ankle-foot orthosis (KAFO). ${ }^{8} \mathrm{~A}$ recent Cochrane review provided evidence that oral steroids improve muscle strength and function in DMD for up to 5 years.9,10 Accordingly, the patients reviewed here were treated with prednisolone $0.75 \mathrm{mg} / \mathrm{kg} /$ day or deflazacort $0.9 \mathrm{mg} / \mathrm{kg} / \mathrm{day}$, once their gross motor skills had reached a plateau or started to decline, which usually coincided with admission to primary school (age 4-6 years). The doses were starting doses that were not regularly adjusted with changes in body weight but were altered depending on the clinical picture. The maximum daily dose for either drug was $40 \mathrm{mg}$. The steroid treatment was generally well tolerated, and the observed adverse effects included increased appetite, weight gain, behavioral problems, high blood pressure, stunted growth, osteoporosis, and cataracts. Prior to commencing treatment, all patients had a blood screen including full blood count, biochemical profile, vitamin D level, and varicella antibodies. If appropriate, children were immunized against chickenpox. A family history of active tuberculosis was a contraindication for steroid treatment of DMD. A steroid alert card was issued to every child reminding health professionals of the possibility of drug-induced adrenal insufficiency. At each clinic visit, weight, height, blood pressure, and forced vital capacity (FVC) were measured, and urine was tested for glucose, protein, and blood. Although no patient with a myasthenic syndrome was among this cohort, the therapeutic options for these rare disorders affecting the neuromuscular junction should be mentioned. Pyridostigmine bromide, 3,4-diaminopyridine and ephedrine sulphate are effective in non-immune congenital myasthenic syndromes, whereas acetyl cholinesterase inhibitors, immunosuppressant drugs, and thymectomy are the treatment of choice for juvenile autoimmune myasthenia gravis. ${ }^{11,12}$ Recent studies suggest a positive effect of oral salbutamol $2 \mathrm{mg}$ thrice daily on muscle power in patients with SMA but the drug was not routinely used in this group. 13,14

\section{Skeletal}

Despite regular physiotherapy and preventative splinting, joint contractures were frequently observed in children with NMDs, and in some they were present from birth (e.g. congenital muscular dystrophy). The commonest type was an ankle-foot contracture which was treated with serial casting or Achilles tendon release by an orthopedic surgeon. ${ }^{15,16}$ At each appointment, the patient's spine was examined for abnormal curvatures (hyperlordosis, scoliosis, and kyphosis) and vertebral fractures. There was a low threshold for requesting spinal $X$ rays or referring to a spinal surgeon for a baseline assessment. Conservative treatment of a scoliosis included a spinal brace, and in severe cases spinal fixation and fusion surgery were performed. ${ }^{17-19}$ Osteopenia was common in boys with DMD, and the added effect of oral steroids increased the incidence of osteoporosis and vertebral and other fractures. ${ }^{20,21}$ The bone mineral density of these children was measured by dual-energy $X$-ray absorptiometry (DEXA scan) every 2 years. Lately, patients commenced on prednisolone or deflazacort were also prescribed the oral bisphosphonate risedronate at a dose of approximately 1 $\mathrm{mg} / \mathrm{kg}$ once weekly (maximum dose $35 \mathrm{mg}$ once weekly) and a combined calcium and vitamin D preparation on 6 days per week. 22,23 DMD patients on steroids diagnosed with a fracture were treated as inpatients with intravenous infusions of pamidronate. Twice-yearly dental checkups were recommended as osteonecrosis of the jaw (ONJ) is a recognized complication of bisphosphonate therapy. 24,25 In children with joint hypermobility, heritable disorders of connective tissue, such as Ehlers-Danlos syndrome, were considered.

\section{Nervous}

Cognitive impairment of varying severity and neuropsychiatric disorders were frequently seen in patients with dystrophinopathies, MD, and other inherited muscle diseases. ${ }^{26-28}$ When assessing young infants, it was important to differentiate between those who had poor truncal but good limb tone (central hypotonia) and those who were floppy and weak (peripheral hypotonia). In children with unknown neuropathy or myopathy, neuroradiological studies and peripheral neurophysiological tests were sometimes helpful. Associated seizures were controlled with standard anti-epileptic drugs (e.g. sodium valproate, carbamazepine). Therapeutic sleep systems and melatonin 3-6 mg at night were prescribed for patients with sleeping difficulties. Occasionally, adolescents with MD and excessive daytime sleepiness were treated with modafinil $100 \mathrm{mg}$ once or twice daily. 29,30 Children with MD and those on long-term steroids were screened for small cataracts annually by an optician or ophthalmologist. Sensorineural deafness was rare but has been reported in MD, facioscapulohumeral muscular dystrophy, and Charcot-Marie-Tooth disease. ${ }^{31}$ Malignant hyperthermia is a serious condition associated 
with general anesthesia and characterized by muscle rigidity, rhabdomyolysis, acidosis, myoglobinuria, and hyperthermia. Patients with a wide range of myopathies can be affected and they were made aware of this risk prior to undergoing surgery. ${ }^{32}$ When patients complained of pain, their symptoms were analyzed according to main site, radiation, character, severity, duration, and frequency. In young children, a simple pain rating scale was used. ${ }^{33}$ If an underlying pathology could be identified, specific treatment was initiated. Leg pain and cramps were frequently seen in children with NMDs and often responded to massage, paracetamol, ibuprofen, a mechanical compression device (Flowtron ${ }^{\circledR}$ ) or transcutaneous electrical nerve stimulation (TENS). A significant number of children had non-organic or psychosomatic pain. 34,35

\section{Cardiovascular}

As cardiac involvement is common in children with NMDs, all patients had a baseline cardiovascular assessment at the time of diagnosis. ${ }^{36}$ Boys with DMD and teenagers with BMD had annual echocardiograms to check for early signs of cardiomyopathy. Regular electrocardiograms were recommended for patients with MD and EmeryDreifuss muscular dystrophy to detect conduction defects that may necessitate anti-arrhythmic drug therapy or a pacemaker. ${ }^{37,38}$ Once the left ventricular ejection fraction started to decrease significantly in DMD patients, treatment with a beta-adrenoceptor blocker (e.g. bisoprolol) and an angiotensin-converting enzyme inhibitor (e.g. perindopril) was commenced.39,40 Occasionally, long-term use of oral steroids led to moderate hypertension. If this was suspected following one abnormal reading, the blood pressure was measured repeatedly on different days using a sphygmomanometer with a cuff covering at least $2 / 3$ of the child's upper arm. Antihypertensive therapy was rarely required and usually initiated by a pediatric nephrologist without stopping the steroids. ${ }^{41}$

\section{Respiratory}

Children with NMDs, particularly those with DMD and SMA, are prone to develop chest infections, which is due to their weak respiratory muscles and their reduced mobility. It was therefore recommended that they should have the pneumococcal and the seasonal influenza vaccines. ${ }^{42}$ Lower respiratory tract infections were treated aggressively with oral or intravenous antibiotics. At each clinic visit, the young patients' lung function was measured using an electronic spirometer with a printer. If symptoms of nocturnal hypoxia and hypercapnia were reported, for instance headaches and tiredness in the morning, an overnight pulse oximetry study was arranged which allowed continuous recording of oxygen saturations and heart rate, and early recognition of desaturations. ${ }^{43,44}$ When a patient's coughing capacity was significantly reduced, a mechanical insufflation/exsufflation device (CoughAssist ${ }^{\circledR}$ ) was prescribed to help removing secretions from the lungs. ${ }^{45} \mathrm{~A}$ steady decline in the FVC (absolute and percent predicted) indicated the need for a referral to the home ventilation team and, usually in the second decade of life, initiation of non-invasive positive pressure ventilation (NIPPV) via a nasal mask, a face mask or a mouthpiece to prevent respiratory failure. A tracheostomy was rarely required. 46,47

\section{Gastrointestinal}

At each consultation, a dietary history was obtained including appetite, length of meal times and difficulties with chewing and swallowing. If recurrent choking episodes were reported, the patient was referred to a specialist speech and language therapist for a formal feeding assessment and a videofluoroscopy study. ${ }^{48}$ Parents were advised to take their children for regular dental appointments to recognize caries and gingivitis early. ${ }^{49}$ The importance of a balanced, highfiber diet was emphasized to improve general well-being and facilitate regular bowel function. Constipation was fairly common and usually responded to lactulose, macrogols, senna or docusate sodium. ${ }^{50}$ Gastroesophageal reflux was treated with aluminum hydroxide and magnesium carbonate or ranitidine. Excessive weight gain was frequently observed in children receiving oral steroids, particularly those on prednisolone, who developed cushingoid features. Some young patients with a NMD did not show adequate weight gain despite input from a dietician and therefore required nasogastric tube feeding or a gastrostomy. ${ }^{51,52}$

\section{Urogenital}

Children with NMDs are prone to dehydration due to their restricted mobility, which can lead to renal impairment. Myoglobinuria is another complication of inherited myopathies and can result in renal failure, if untreated. The protein myoglobin is released from damaged muscle fibers and causes brown discoloration of the urine which tests positive for blood on dipstick analysis. Older children were advised to avoid excessive exercise and encouraged to drink plenty of fluids, particularly during the summer months. ${ }^{53-55}$ Nocturnal and diurnal enuresis was treated with desmopressin or oxybutynin in children who did not have associated global developmental delay. ${ }^{56}$ Symptoms of a urinary tract infection were investigated promptly and managed according to current guidelines. ${ }^{57}$

\section{Conclusion}

Although the timely management of medical problems had priority in the children followed up here, there were other issues such as education and social integration that contributed to the quality of life of the patients and their families. Most children with NMDs attended a nursery or 
(special) school during the day and had a statement of special educational needs. Their treatment and any adaptations made to the family homes were funded by the National Health Service and local social services departments. Some children were offered respite care in a hospice. The transition period from adolescence to adulthood often lasts longer in young people with a chronic disease or disability, and a number of patients were seen in the pediatric muscle clinic beyond the British upper age limit of 16 years. In a recent survey, adult physicians in the United States expressed concern about their lack of training in childhood-onset conditions which may hinder a smooth transition of care for affected adolescents. ${ }^{58}$ This problem will not occur, if children and adults with NMDs receive their specialist care by the same multidisciplinary team throughout their lives as is practice in some centers in Great Britain. Where this solution is not feasible, additional postgraduate training for doctors is required specifically addressing transition care. Finally, there remains hope that a few of the novel therapeutic agents that are currently tested in multicenter trials will become a successful treatment for one or more neuromuscular diseases in the future. ${ }^{59}$

\section{Acknowledgements}

I would like to thank the members of the pediatric muscle team in Newcastle upon Tyne for their continued support.

\section{References}

1. Strehle EM. Food for thought: autophagic vacuolar myopathies. Arch Dis Child. 2009;94:567-9.

2. Jain Foundation Inc. Orchestrating a cure for LGMD2B/Miyoshi [website]. https://www.jain-foundation.org/projects.php. Access: 09/03/2009.

3. Manzur AY, Kinali M, Muntoni F. Update on the management of Duchenne muscular dystrophy. Arch Dis Child. 2008;93:986-90.

4. Eagle M, Bourke J, Bullock R, Gibson M, Mehta J, Giddings D, et al. Managing Duchenne muscular dystrophy - the additive effect of spinal surgery and home nocturnal ventilation in improving survival. Neuromuscul Disord. 2007;17:470-5.

5. Iannaccone ST. Modern management of spinal muscular atrophy. J Child Neurol. 2007;22:974-8.

6. Muscular Dystrophy Campaign [website]. http://www.musculardystrophy.org/how_we_help_you/for_professionals/clinical_ databases. Access: 09/03/2009.

7. Steffensen B, Hyde S, Lyager S, Mattsson E. Validity of the EK scale: a functional assessment of non-ambulatory individuals with Duchenne muscular dystrophy or spinal muscular atrophy. Physiother Res Int. 2001;6:119-34.

8. Bakker JP, de Groot IJ, Beckerman $\mathrm{H}$, de Jong BA, Lankhorst GJ. The effects of knee-ankle-foot orthoses in the treatment of Duchenne muscular dystrophy: review of the literature. Clin Rehabil. 2000;14:343-59.

9. Manzur AY, Kuntzer T, Pike M, Swan A. Glucocorticoid corticosteroids for Duchenne muscular dystrophy. Cochrane Database Syst Rev. 2008; (1):CD003725.

10. Ciafaloni E, Moxley RT. Treatment options for Duchenne muscular dystrophy. Curr Treat Options Neurol. 2008;10:86-93.
11. Kinali $M$, Beeson $D$, Pitt $M C$, Jungbluth $H$, Simonds AK, Aloysius A, Cockerill H, Davis T, Palace J, Manzur AY, Jimenez-Mallebrera C, Sewry C, Muntoni F, Robb SA. Congenital myasthenic syndromes in childhood: diagnostic and management challenges. J Neuroimmunol. 2008;201-202:6-12.

12. Forsyth R, Newton R. Paediatric Neurology. Oxford: University Press, 2007.

13. Angelozzi C, Borgo F, Tiziano FD, Martella A, Neri G, Brahe C. Salbutamol increases SMN mRNA and protein levels in spinal muscular atrophy cells. J Med Genet. 2008;45:29-31.

14. Pane M, Staccioli S, Messina S, D'Amico A, Pelliccioni M, Mazzone ES, et al. Daily salbutamol in young patients with SMA type II. Neuromuscul Disord. 2008; 18:536-40.

15. Main M, Mercuri E, Haliloglu G, Baker R, Kinali M, Muntoni F. Serial casting of the ankles in Duchenne muscular dystrophy: can it be an alternative to surgery? Neuromuscul Disord. 2007;17:227-30.

16. Burns J, Ryan MM, Ouvrier RA. Evolution of foot and ankle manifestations in children with CMT1A. Muscle Nerve. 2009;39:158-66.

17. Cheuk DK, Wong V, Wraige E, Baxter P, Cole A, N'Diaye T, et al. Surgery for scoliosis in Duchenne muscular dystrophy. Cochrane Database Syst Rev. 2007;(1):CD005375.

18. Mullender M, Blom N, De Kleuver M, Fock J, Hitters W, Horemans $A$, et al. A Dutch guideline for the treatment of scoliosis in neuromuscular disorders. Scoliosis. 2008;3:14.

19. Kotwicki T, Jozwiak M. Conservative management of neuromuscular scoliosis: personal experience and review of literature. Disabil Rehabil. 2008;30:792-8.

20. King WM, Ruttencutter R, Nagaraja HN, Matkovic V, Landoll J, Hoyle $C$, et al. Orthopedic outcomes of long-term daily corticosteroid treatment in Duchenne muscular dystrophy. Neurology. 2007;68:1607-13.

21. Houde S, Filiatrault M, Fournier A, Dube J, D'Arcy S, Berube D, et al. Deflazacort use in Duchenne muscular dystrophy: an 8-year follow-up. Pediatr Neurol. 2008;38:200-6.

22. Russell RG. Biphosphonates: mode of action and pharmacology. Pediatrics. 2007;119 Suppl 2:S150-62.

23. Mok CC, Tong $\mathrm{KH}$, To $\mathrm{CH}$, Siu YP, Ma KM. Risedronate for the prevention of bone mineral density loss in patients receiving high-dose glucocorticoids: a randomized double-blind placebocontrolled trial. Osteoporos Int. 2008;19:357-64.

24. Cartsos VM, Zhu S, Zavras AI. Biphosphonate use and the risk of adverse jaw outcomes: a medical claims study of 714,217 people. J Am Dent Assoc. 2008;139:23-30.

25. Chahine C, Cheung MS, Head TW, Schwartz S, Glorieux FH, Rauch F. Tooth extraction socket healing in pediatric patients treated with intravenous pamidronate. J Pediatr. 2008;153:719-20.

26. D'Angelo MG, Bresolin N. Cognitive impairment in neuromuscular disorders. Muscle Nerve. 2006;34:16-33.

27. Young HK, Barton BA, Waisbren S, Portales Dale L, Ryan MM, Webster RI, et al. Cognitive and psychological profile of males with Becker muscular dystrophy. J Child Neurol. 2008;23:155-62.

28. Hendriksen JG, Vles JS. Neuropsychiatric disorders in males with Duchenne muscular dystrophy: frequency rate of attentiondeficit hyperactivity disorder (ADHD), autism spectrum disorder, and obsessive-compulsive disorder. J Child Neurol. 2008;23:477-81.

29. Quera Salva MA, Blumen M, Jacquette A, Durand MC, Andre S, De Villiers $M$, et al. Sleep disorders in childhood-onset myotonic dystrophy type 1 . Neuromuscul Disord. 2006;16:564-70.

30. Kumar R. Approved and investigational uses of modafinil: an evidence based review. Drugs. 2008;68:1803-39.

31. Auer-Grumbach M. Hereditary sensory neuropathy type I. Orphanet J Rare Dis. 2008;3:7.

32. Hayes J, Veyckemans F, Bissonnette B. Duchenne muscular dystrophy: an old anesthesia problem revisited. Paediatr Anaesth. 2008; 18:100-6. 
33. Decruynaere C, Thonnard JL, Plaghki L. How many response levels do children distinguish on faces scales for pain assessment? Eur J Pain. In press 2009.

34. Engel JM, Kartin D, Jaffe KM. Exploring chronic pain in youths with Duchenne Muscular Dystrophy: a model for pediatric neuromuscular disease. Phys Med Rehabil Clin N Am. 2005;16:1113-24.

35. Clinch J, Eccleston C. Chronic musculoskeletal pain in children: assessment and management. Rheumatology (Oxford). 2009;48:466-74.

36. Finsterer J, Stöllberger C. Primary myopathies of the heart. Scand Cardiovasc J. 2008;42:9-24.

37. Sovari AA, Bodine CK, Farokhi F. Cardiovascular manifestations of myotonic dystrophy-1. Cardiol Rev. 2007;15:191-4.

38. Finsterer J, Stöllberger C. Atrial fibrillation/flutter in myopathies. Int J Cardiol. 2008;128:304-10.

39. Duboc D, Meune C, Pierre B, Wahbi K, Eymard B, Toutain $A$, et al. Perindopril preventive treatment on mortality in Duchenne muscular dystrophy: 10 years' follow-up. Am Heart J. 2007; 154:596-602.

40. Ogata $H$, Ishikawa $Y$, Ishikawa $Y$, Minami R. Beneficial effects of beta-blockers and angiotensin-converting enzyme inhibitors in Duchenne muscular dystrophy. J Cardiol. 2009;53:72-8.

41. Johnson MC, Schneider CJ, Beck AM. Management of systemic hypertension in children and adolescents: an update. Curr Treat Options Cardiovasc Med. 2007;9:381-90.

42. United Kingdom. Department of Health. [website]. http://www. dh.gov.uk/en/AdvanceSearchResult/index.htm?searchTerms $=$ gr een+book. Access: 09/03/2009.

43. Bushby K, Bourke J, Bullock R, Eagle M, Gibson M, Quinby J. The multidisciplinary management of Duchenne muscular dystrophy. Curr Paediatr. 2005;15:292-300.

44. Kang SW. Pulmonary rehabilitation in patients with neuromuscular disease. Yonsei Med J. 2006;47:307-14.

45. Homnick DN. Mechanical insufflation-exsufflation for airway mucus clearance. Respir Care. 2007;52:1296-305.

46. Robert D, Argaud L. Clinical review: long-term noninvasive ventilation. Crit Care. 2007;11:210.

47. Ozsancak A, D'Ambrosio C, Hill NS. Nocturnal noninvasive ventilation. Chest. 2008;133:1275-86.

48. Aloysius A, Born P, Kinali M, Davis T, Pane M, Mercuri E. Swallowing difficulties in Duchenne muscular dystrophy: indications for feeding assessment and outcome of videofluoroscopic swallow studies. Eur J Paediatr Neurol. 2008;12:239-45.
49. Engvall M, Sjögreen L, Kjellberg H, Robertson A, Sundell S, Kiliaridis S. Oral health in children and adolescents with myotonic dystrophy. Eur J Oral Sci. 2007;115:192-7.

50. Pijpers MA, Tabbers MM, Benninga MA, Berger MY. Currently recommended treatments of childhood constipation are not evidence based: a systematic literature review on the effect of laxative treatment and dietary measure. Arch Dis Child. 2009;94:117-31.

51. Philpot J, Bagnall A, King C, Dubowitz V, Muntoni F. Feeding problems in merosin deficient congenital muscular dystrophy. Arch Dis Child. 1999;80:542-7.

52. Messina S, Pane M, De Rose P, Vasta I, Sorleti D, Aloysius A, et al. Feeding problems and malnutrition in spinal muscular atrophy type II. Neuromuscul Disord. 2008;18:389-93.

53. Garrood P, Eagle M, Jardine PE, Bushby K, Straub V. Myoglobinuria in boys with Duchenne muscular dystrophy on corticosteroid therapy. Neuromuscul Disord. 2008;18:71-3.

54. Aboumousa A, Hoogendijk J, Charlton R, Barresi R, Herrmann $\mathrm{R}$, Voit $\mathrm{T}$, et al. Caveolinopathy - new mutations and additional symptoms. Neuromuscul Disord. 2008;18:572-8.

55. Van Adel BA, Tarnopolsky MA. Metabolic myopathies: update 2009. J Clin Neuromuscul Dis. 2009;10:97-121.

56. Ellsworth $P$, Caldamone A. Pediatric voiding dysfunction: current evaluation and management. Urol Nurs. 2008 28:249-57.

57. Coulthard MG, Lambert HJ, Keir MJ. Do systemic symptoms predict the risk of kidney scarring after urinary tract infection? Arch Dis Child. 2009;94:278-81.

58. Peter NG, Forke CM, Ginsburg KR, Schwarz DF. Transition from pediatric to adult care: internists' perspectives. Pediatrics. 2009;123:417-23.

59. Wagner KR. Approaching a new age in Duchenne muscular dystrophy treatment. Neurotherapeutics. 2008;5:583-91.

Correspondence:

Eugen-Matthias Strehle

Consultant Pediatrician, Honorary Consultant in Neuromuscular Genetics

Department of Pediatrics, North Tyneside General Hospital

Rake Lane, North Shields NE29 8NH - United Kingdom

Tel.: +44 (191) 203.1200

Fax: +44 (191) 293.2520

E-mail: strehle@doctors.org.uk 